\title{
A Critical Thinking of the Researches on Writing Self-Efficacy in Second Language Learning
}

\author{
Zhan Rong \\ City College of Wuhan University of Science and Technology \\ Wuhan, China
}

\begin{abstract}
The aim of this paper is to find out some research gaps on writing self-efficacy in Second Language Learning (SLL). Having reviewed the studies centered upon the relationship between writing self-efficacy and writing proficiency, writing self-efficacy and writing strategy use as well as writing selfefficacy training, we made a critique of the studies based on the criteria including the variability of sampling, the reliability of the data, the objectivity and comprehensiveness of data analysis. The results suggest that the current studies could be improved with a wider range of subjects both in quantity and academic proficiency. In addition, we also call for a more coherent standard in writing proficiency judgement. In addition, it's worth more follow-up studies on the possible mutual influence among different variables. Finally, qualitative research methods are apt to be introduced to examine the working mechanism of writing self-efficacy training.
\end{abstract}

Keywords-researches; writing self-efficacy; writing proficiency; writing strategy use; Second Language Learning (SLL)

\section{INTRODUCTION}

In terms of his social cognitive theory, Bandura [2] defines self-efficacy as "People's judgments of their capabilities to organize and execute courses of action required to attain designated types of performances”. According to [1], there are mainly four sources of self-efficacy: enactive mastery, vicarious experience, verbal persuasion and psychological and affective state. Mastery experiences are seen as one of the most influential factors affecting the strength of one's self-efficacy. The more success students obtain from their performance in learning, the greater self-efficacy students can feel; people may get vicarious experience when they observe others engaged in the task. When they see their peers successfully perform a learning task, they may believe that they can also execute the same learning task effectively; the self-efficacy of learners can also be fostered by persuasions, remarks and comments from others, such as parents, teachers and their trustworthy peers; emotional states such as anxiety, stress or mood can also influence self-efficacy. If learners experience negative feelings like fears, horrors etc., their self-efficacy is very likely to be reduced.

In terms of [12] and [11], people with high self-efficacy are often more likely to work harder with longer persistence and more positive emotional states, and are hypothesized to take more challenging learning tasks and achieve at higher levels. On the contrary, those with low self-efficacy are prone to choose easy tasks to avoid failures.
Quite a few empirical researches have centered upon the relationship between self-efficacy and academic achievement, which suggested that self-efficacy, could have an influence over academic achievement to different degrees. Zimmerman, Bandura and Martinez-Pons [11] studied the role of selfefficacy and goal setting in self-motivated academic proficiency, and they found that students' self-efficacy for academic proficiency affected their goal setting for themselves and their achievement; After 36 studies with 4998 subjects concerned, Multon, Brown and Lent, cited in [6], found that self-efficacy was related to academic performance, and they reported that self-efficacy accounted for $14 \%$ of variance in students' academic performance.

As a subcategory of self-efficacy, writing self-efficacy was defined by [8] as follows: "learners' judgment of their capability to successfully perform various writing skills appropriate to their academic level” (p.214). In the context of SLL, researchers tend to focus on the roles that writing selfefficacy play in the acquisition of writing skills.

\section{RESEARCHES ON WRITING SELF-EFFICACY IN SLL}

Among the studies on writing self-efficacy in SLL, the relationship between writing self-efficacy and writing proficiency draws concern. McCarthy, Meier and Rinderer [5] invented an instrument aiming at examining students' writing self-efficacy in using 19 identified writing skills. This instrument as well as writing tasks was administered to students respectively. Students' writing proficiency was judged by four raters. The analysis of the result showed that there was a significant positive correlation between the writing selfefficacy and writing proficiency.

Pajares and Johnson [6] studied the writing self-efficacy, writing outcome expectations, writing apprehension, personal self-efficacy and writing proficiency of 30 undergraduates. The study lasted for one semester. At the beginning and the end of the semester each, subjects were asked to write a 20-30 minute essay and investigated by the set of instrument containing scales or tests which aimed at examining their writing selfefficacy, writing outcome expectations, writing apprehension, and personal self-efficacy. In the posttest at the end of the semester, the above process was repeated. According to the regression analysis, they found that writing self-efficacy was positively related to writing proficiency in both the pretest and the posttest. 
There're also studies about the relationship between writing self-efficacy and strategy use. Graham and Harries, cited in [9], taught a group of students with disabilities some strategies for writing essays and stories, which then has proved that this strategy teaching can help improve students' writing selfefficacy. They integrated the strategy teaching with normal instructional practice. During the training, they reminded learners of the importance of strategies, demonstrated the implementation of strategies and required them to monitor and evaluate the progress by themselves.

Schunk and Swartz [9] studied the influence of goal setting and progress feedback on writing self-efficacy and writing proficiency through writing strategy instruction with a group of gifted and average-ability students. They divided the students into three groups: process-goal children plus feedback (children given a process goal of learning the strategy and receiving feedbacks from their teachers linked to their use of strategies), product-goal children (children given a product goal of writing paragraphs) and general-goal children (children given a general goal of working productively). After one-semester instruction, process-goal children plus feedback were found to outperform the children in other two groups both on writing self-efficacy and writing proficiency. It's also proved that students' writing self-efficacy was positively correlated with strategy use.

With regard to writing self-efficacy training, Garcia and Caso [4] gave writing self-efficacy training to some children with writing disabilities. There're ten sessions for this training, which focused on introducing or consolidating the four selfefficacy resources. For enactive mastery, researchers designed writing activities with a low level of difficulty to help poor learners obtain more successful writing experience, and formative assessment rather than summative assessment was given in each step of learning; vicarious experience was cultivated by group work. Students who made progress rather than obtained a high mark were set as learning models for the rest. During the training session, researchers provided positive reinforcement for students and encouraging them to keep on trying through oral praise or written feedback on their compositions. To introduce and consolidate a positive psychological state, the instructors tried to reduce students' anxiety on English writing and inspire them to focus more on learning process rather than learning outcome. Moreover, schedule practice sessions were given optimally in order to help students set attainable goals. After the training, the result revealed an increase in students' writing self-efficacy, and they were also found to have their written products improved after the training.

\section{A CRITIQUE OF THE RESEARCHES ON WRITING SELF- EFFICACY}

A closer observation towards the above researches shows that quantitative methods are widely applied in the studies. To make a judgment on whether quantitative researches are reliable or not, we may take the following issues into consideration [3]: 1) Is the sampling representative enough? 2) Do the instruments (e.g. surveys or questionnaires) have a good reliability and validity? 3) Are all the variables well-controlled to ensure the data a high accuracy? 4) Is the data analysis objective and comprehensive enough? 5) Is there any possibility that some pre-existing bias of the researchers could be detected?

There're two variables in the research made by [5]: writing self-efficacy and writing proficiency. They designed an instrument to investigate students' writing self-efficacy in using 19 identified writing skills. The selection of those writing skills was worth challenging. Were these 19 writing skills inclusive and typical? To what extent could the data drawn from the instrument reflect the level of students' writing selfefficacy? With regard to writing proficiency, students were assigned to perform a writing task and their written products were judged by four raters. Obviously, the researchers noticed the inevitable subjectivity in marking written works, so they invited four raters to make the judgment as objective as possible. However, there're some other things in need of further consideration. To begin with, was the writing task appropriate to students' academic level? It's believed that the writing task, either too easy or too difficult, may fail to identify the actual writing proficiency of the students. Moreover, although the written products were evaluated by four raters to have the subjectivity reduced to the lowest level, yet some problems may still exist. For instance, did all the raters judge the written products based on the same standard? If there's significant divergence among the four raters upon one composition, what would be done to compensate for a comparatively fair judgement of the author's writing proficiency?

Pajares and Johnson [7] focused on five variables. Their subjects were 30 undergraduates, which was a comparatively small sample. Different from the one conducted by [5], they did the research for a semester and gave the data analysis twice in the pretest and the posttest. Both analyses suggested a positive correlation between writing proficiency and writing self-efficacy, which backed up the conclusion drawn by [5] but turned to be more convincing. Yet the two researches only identified the correlation between writing proficiency and writing self-efficacy, it might go further on the possible interactive influence between the two variables. Is there any possibility that writing self-efficacy would affect writing proficiency? Pajares [8] contends that self-efficacy makes a powerful and independent contribution to the prediction of achievement; can this also be verified in the writing context of SLL?

Graham and Harries, cited in [9], made an exploration of the relationship between writing self-efficacy and strategy use. Their subjects were a group of students with disabilities. This sampling was found to be specialized, thus a doubt might be aroused about whether the conclusion was applicable to the majority of common students. In this sense, the conclusion might be at the risk of being overgeneralized. The researchers blended the strategy training with normal instructional practice, and finally concluded that the strategy teaching could help improve students' writing self-efficacy. In this case, explanation should be given to show how the strategy teaching enhanced students' writing self-efficacy. Bandura [1] named four main sources of self-efficacy: enactive mastery, vicarious experience, verbal persuasion and psychological and affective state. The researchers need to illustrate how the strategy teaching contributed to enrich these sources of self-efficacy. 
For instance, did the students accumulate more enactive mastery by effectively performing certain writing strategies? Or did the students obtain vicarious experience by seeing their peers successfully apply specific strategies in writing? Or did the teachers' instruction encouraged students and cultivated them a positive affective state so as to strengthen their selfefficacy?

The research done by [10] was about the influence of goal setting and progress feedback on writing self-efficacy. On the issue of sampling, the researchers highlighted the variety of the subjects, including gifted and average-ability of the students. But the sample might be more desirable if students with belowaverage ability could be involved. There're three experimental groups in this one-semester study: process-goal children plus feedback; product-goal children; general-goal children. It turned out that the children in the first group obtained more self-efficacy than those from other two groups in the posttest. Yet the researchers were also expected to show how the process-goal and feedbacks contributed to the four sources of self-efficacy.

Self-efficacy training was regarded as a more dynamic approach to examine the functioning of self-efficacy in the learning process compared to the above researches, but it's questionable whether all the measures in the training session were effective and practical. For instance, if the sampling was a much larger one, how could the formative assessment is given to each student timely? How should the teacher divide students to ensure them more vicarious experience in their working groups? Garcia and Caso [4] claimed the level of students' writing self-efficacy was enhanced after training, but further explanations were also expected to give on how the training worked. To make it, qualitative methods like interviews or diary-keeping could help to take a closer observation towards students' cognitive activities and affective status; in turn the researchers would dig out the influential factors that lead to the increase of writing self-efficacy. Take the interview for example, the researcher could ask students the following questions such as "How did you think about the writing tasks? What made you think that the tasks were difficult/easy to accomplish?", or "How did you feel while performing writing tasks? Why did you have such kind of feeling? ", or "How did your teachers encourage you in the writing class? In what way did you think that teachers helped you improve your writing? "The answers might help deepen the interpretation of writing self-efficacy increase after the training. Besides, students were reported to make a progress in their writing after the writing self-efficacy training, which indicated that the training might have something to do with the improvement of the writing performance. Such a finding was supposed to be pushed forward by more studies centered upon the following questions: 1) Is there any cause-and-effect relationship between the increase in writing self-efficacy and the improvement of writing performance? 2) Is it possible that the improved writing performance was attributed to other factors (e.g. the accumulation of more knowledge in writing, the better use of writing strategies, the administering of easier writing tasks etc.) instead of the increase in self-efficacy?

\section{CONCLUSION}

On the basis of the discussion above, the studies upon writing self-efficacy could be improved in the following aspects: The sampling should cover a wider range of subjects both in quantity and academic proficiency; the judgement of writing proficiency is expected to invite a more comprehensive and coherent standard, and a mechanism in resolving sharp divergence among raters also needs to be introduced. Moreover, instead of merely focusing on the correlation between writing self-efficacy and writing proficiency, or the one between writing self-efficacy and writing strategy use, researchers could explore the possible mutual effect among these variables. As for writing self-efficacy training, a more authoritative model needs to be established, and qualitative methods can be introduced to investigate the influential factors behind the change in writing self-efficacy. It's hoped that more researches would be done in this domain to facilitate the learning of second language writing.

\section{REFERENCES}

[1] Bandura, A. Self-Efficacy: Toward A Unifying Theory of Behavioral Change [J]. Psychological Review, 1977a(84): 191-215.

[2] Bandura, A. Social Foundations of Thought and Action: A Cognitive Theory [M]. Engelwood Cliffs, NJ: Prentice Hall, 1986.

[3] Browne, N. \& Keeley, S. Asking The Right Questions: A Guide to Critical Thinking [M]. Beijing: China Machine Press, 2015.

[4] Garcia, J. N. \& Caso, A, M. Changes in Writing Self-Efficacy and Writing Products and Processes Through Specific Training in The SelfEfficacy Beliefs of Students with Learning Disabilities [J]. Learning Disabilities: A Contemporary Journal, 2006(4): 1-27.

[5] McCarthy, P., Meier, S., \& Rinder, R. Self-Efficacy and Writing: A Different View of Self-Evaluation [J]. College Composition and Education, 1985(36): 465-471.

[6] Pajares, F. \& Johnson, M. Confidence and Competence in Writing: The Role of Self-Efficacy, Outcome Expectancy and Apprehension [J]. American Educational Research Journal, 1993(7): 143-168.

[7] Pajares, F. \& Johnson, M. The Role of Self-Efficacy Beliefs in the Writing Performance of Entering High School Students: A Path Analysis [J]. American Educational Research Journal, 1995(8): 1-33.

[8] Pajares, F. Self-Efficacy During Childhood and Adolescence [J]. SelfEfficacy Beliefs of Adolescents, 2001(12): 339-367.

[9] Schunk, D. H. Self-Efficacy for Reading and Writing: Influence on Modeling, Goal Setting and Self-Evaluation [J]. Reading and Writing Quarterly, 2003(19): 159-172.

[10] Schunk, D. H. \& Swartz, C. W. Goals and Process Feedback: Effects on Self-Efficacy and Writing Achievement [J]. Journal of Educational Research, 1993 (29): 150-155.

[11] Schunk, D. H.\& Zimmerman, B. J. Influencing Children's Self-Efficacy and Self-Regulation of Reading and Writing Through Modeling [J]. Reading and Writing Quarterly, 2007(23): 7-25.

[12] Walker, B. J. The Cultivation of Student Self-Efficacy in Reading and Writing [J]. Reading and Writing Quarterly, 2003(19): 173-187.

[13] Zimmerman, B. J., Bandura, A. \& Martinez-Pons, M. Self-Motivation for Academic Achievement: The Role of Self-Efficacy Beliefs and Personal Goal Setting [J]. American Educational Research Journal, 1992(29): 663-676. 